ARTICLE

https://doi.org/10.1038/s41467-020-19348-x

\title{
Site-switchable mono-O-allylation of polyols
}

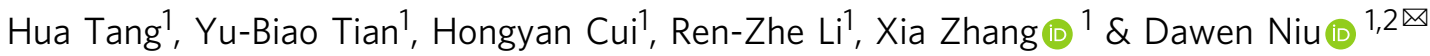

Site-selective modification of complex molecules allows for rapid accesses to their analogues and derivatives, and, therefore, offers highly valuable opportunities to probe their functions. However, to selectively manipulate one out of many repeatedly occurring functional groups within a substrate represents a grand challenge in chemistry. Yet more demanding is to develop methods in which alterations to the reaction conditions lead to switching of the specific site of reaction. We report herein the development of a Pd/Lewis acid co-catalytic system that achieves not only site-selective, but site-switchable mono-O-allylation of polyols with readily available reagents and catalysts. Through exchanging the Lewis acid additives that recognize specific hydroxyls in a polyol substrate, our system managed to install a versatile allyl group to the target in a site-switchable manner. Our design demonstrates remarkable scope, and is amenable to the direct derivatization of various complex, bioactive natural products.

\footnotetext{
${ }^{1}$ Department of Emergency, State Key Laboratory of Biotherapy, West China Hospital, and School of Chemical Engineering, Sichuan University, 610041 Chengdu, China. ${ }^{2}$ State Key Laboratory of Natural Medicines, China Pharmaceutical University, 210009 Nanjing, China. ${ }^{凶}$ email: niudawen@scu.edu.cn
} 
M

olecules containing multiple copies of the same functional group are ubiquitous in Nature and in drug candidates. Site-selective transformations-reactions that can manipulate one of these repeating functional groups while keeping others unaffected-provide efficient access to analogues and derivatives of these compounds, thereby facilitating the interrogation and exploitation of their properties ${ }^{1,2}$. The same kind of functional groups tend to undergo similar transformations, however, and differentiation typically only occurs due to subtle steric and electronic environments. Accordingly, to achieve high site-selectivity following a generalizable strategy remains a significant task in chemistry ${ }^{3-8}$. Even more demanding is the development of methods in which alterations to the reaction conditions result in switching of the specific site of reaction (Fig. 1a), since it necessitates the selective modification at positions that are inherently less reactive ${ }^{9-16}$.

Polyhydroxylated natural products, carbohydrates in particular, play critical roles in virtually all biological processes and they are essential components of many pharmaceuticals (Fig. 1b). Rapid access to the derivatives of these compounds holds tremendous opportunities to understand and modulate key biological processes $^{17-19}$. Polyols contain numerous hydroxyl groups that offer excellent opportunities for derivatization. Manipulation of only one or a certain few hydroxyls in the presence of many others in these substrates, however, used to rely heavily on protection/ deprotection sequences ${ }^{20}$. Regardless, recent studies have shown great promise and potential for the direct, site-selective modification of polyols. In this realm, various methods ${ }^{21,22}$ have been established to selectively modify the intrinsically most reactive hydroxyl groups within a substrate (substrate control). Recently, systems that can override the intrinsic reactivity preferences and accomplish catalyst-controlled, site-switchable modification of complex polyols have emerged ${ }^{23-35}$. As eminent examples, in a series of landmark studies, the Miller group ${ }^{23-26}$, has identified several oligopeptide-based catalysts that enabled site-switchable modification of complex antibiotics, such as vancomycin, teicoplanin, and erythromycin. In these studies, the oligopeptide catalysts were designed as mimetics of the catalytic domains of enzymes. Kawabata et al. ${ }^{29-31}$ devised chiral pyridine derivatives that were used in the site-selective modification of C4$\mathrm{OH}$ of glucopyranosides as well as natural products such as lanatoside $\mathrm{C}$ and avermectin $\mathrm{B}_{2 \mathrm{a}}$. The Tan group ${ }^{32}$ invented a pair of pseudoenantiomeric imidazole-based catalysts that allow sitedivergent modification of polyols containing cis-1,2-diol moieties, including anticancer agent digitoxin. Nargony and coworkers ${ }^{33}$ employed chiral phosphoric acid catalysts to accomplish siteswitchable glycosylation of 6-deoxy erythronolide. Our group ${ }^{34}$ reported the site-divergent $O$-propargylation of various monosaccharides as well as digitoxin employing a pair of chiral $\mathrm{Cu}-$ catalysts. These achievements notwithstanding, to develop general systems that can achieve catalyst-controlled, switchable siteselectivity still represents a challenge. In particular, methods capable of introducing a metabolically stable ether bond remain rather limited.

a
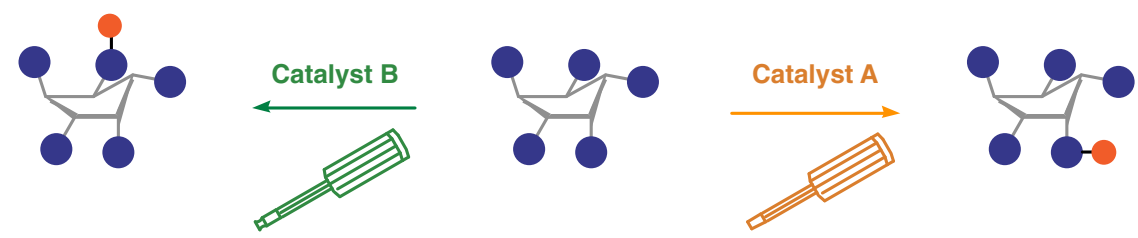

$=$ A functional group

b<smiles>OCC1O[C@H](C[C@@]2(CO)O[C@H](CO)[C@@H](O)[C@H]2O)[C@H](O)[C@H](O)[C@@H]1O</smiles>

Sucrose

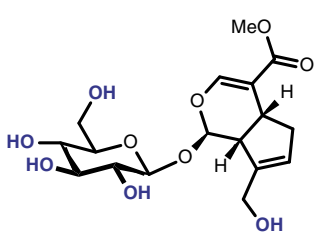

Geniposide

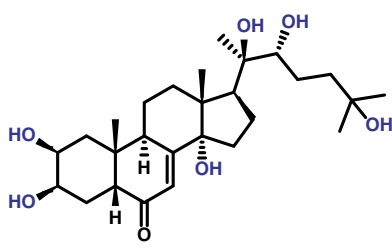

20-Hydroxyecdysone

C
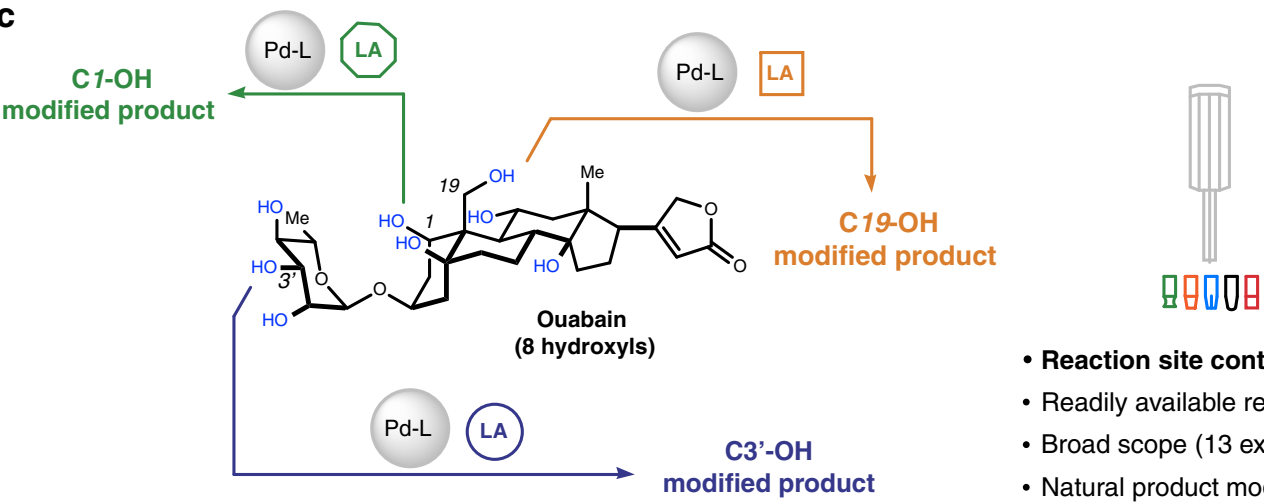

- Reaction site controlled by LA

- Readily available reagents/catalysts

- Broad scope (13 examples)

- Natural product modification

Fig. 1 Site-switchable modification of molecules containing multiple identical functional groups. a Reagent/catalyst-controlled, site-selective modification of complex molecules: a challenge in synthetic chemistry. b Some representative, naturally occurring polyols. c Pd/Lewis acid co-catalyzed, site-switchable modification of polyols (this work). 
a
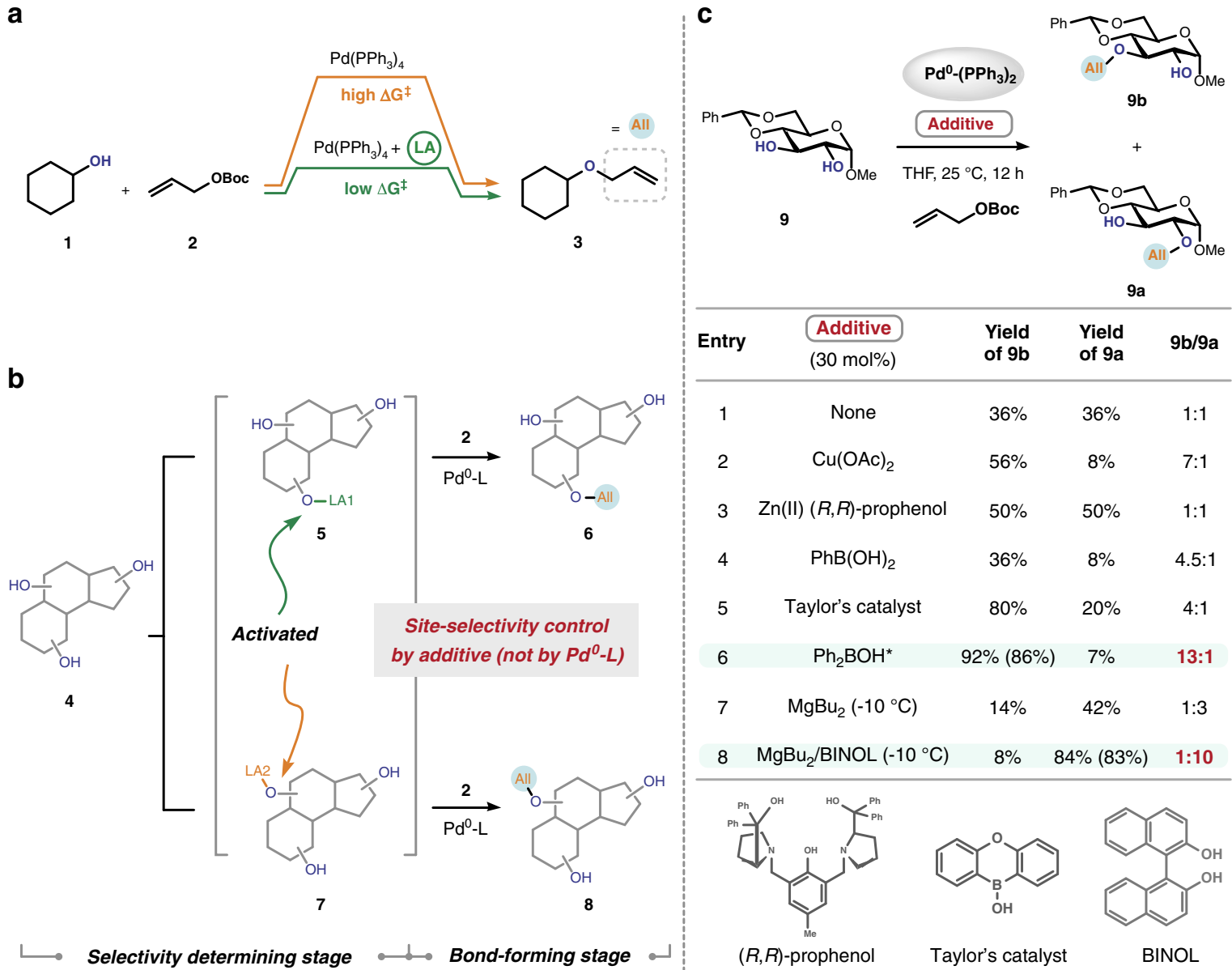

$(R, R)$-prophenol

Taylor's catalyst

INOL

Fig. 2 Mechanistic underpinning and reaction design. a The Pd-catalyzed O-allylation of aliphatic alcohols is accelerated by addition of Lewis acids. b Our reaction design: the use of different Lewis acids (LA) to control site-selectivity. c Initial realization of site-switchable modification of polyols by exchanging additives. Feactions were performed on a $0.2 \mathrm{mmol}$ scale. Product ratios were determined by ${ }^{1} \mathrm{H}$-nuclear magnetic resonance (NMR) analysis of crude reaction mixtures. Yields in parenthesis are isolated yields. $\mathrm{Pd}^{0}-\left(\mathrm{PPh}_{3}\right)_{2}$ used in this study was generated in situ from $\mathrm{Pd}_{2} \mathrm{dba}_{3} \bullet \mathrm{CHCl}_{3}$ and $\mathrm{PPh}_{3}$. ${ }^{\star} \mathrm{Generated}$ in situ from the commercial $\mathrm{Ph}_{2} \mathrm{BOCH}_{2} \mathrm{CH}_{2} \mathrm{NH}_{2}$. Ac acetyl, Ph phenyl, Boc $t$-butoxycarbonyl, Bu butyl, THF tetrahydrofuran, BINOL 1,1'-bi-2-naphthol, dba dibenzylideneacetone.

Here we report a strategy that enables site-switchable mono-Oallylation of polyols by $\mathrm{Pd} /$ Lewis acid co-catalysis ${ }^{36}$. As a distinct feature of our system, the task of activating electrophiles and that of controlling site-selectivity were allocated, respectively, to the Pd-catalyst and the Lewis acid additive. Resembling the role of a gRNA in the Cas/gRNA ${ }^{37}$ system, the Lewis acid additive serves as a guide in our system, and determines the site of reaction in the modification of various polyols (Fig. 1c). Interestingly, such a strategy is akin to the switchable screwdrivers we use in our daily lives. The potential of this principle, however, has not been systematically explored and exploited in chemistry to develop siteselective methodologies. The derivatization of cardiac glycoside ouabain provides an excellent example to illustrate our strategy. As will be discussed in more detail below, using the same Pdcatalyst to activate the electrophile but changing the identity of the specific Lewis acid additive, we accomplish highly selective allylation of the $\mathrm{C} 1-\mathrm{OH}, \mathrm{C} 3$ '-OH, or $\mathrm{C} 19-\mathrm{OH}$ of ouabain (Fig. 1c).

\section{Results}

Reaction design. We were interested in the selective $O$-allylation of polyols because the allyl group is among the smallest, yet most versatile, units in chemistry ${ }^{38}$. Among all of the allylic alkylation methods established to date, a well-studied and often utilized one is the Pd-catalyzed Tsuji-Trost reaction ${ }^{39}$. Intriguingly, the allylation of aliphatic alcohols by the Tsuji-Trost reaction is often a slow process $(\mathbf{1}+\mathbf{2}$ to $\mathbf{3}$, Fig. 2 a, orange arrow), but it can be accelerated by using Lewis acid additives (Fig. 2a, green arrow, and Supplementary Fig. 2 in Supplementary Information). The Lewis acid additives presumably function through complexing with hydroxyls, which would enhance their acidity and facilitate their deprotonation, thereby increasing their nucleophilicity ${ }^{39}$. Our initial supposition was that the unique reactivity of aliphatic alcohols in the Tsuji-Trost reaction could be leveraged to achieve reagent-controlled site-selectivity during the modification of polyols. Specifically, we reasoned that if a Lewis acid additive (e.g., LA1 or LA2 in Fig. 2 b) could be identified to selectively complex with a certain hydroxyl and enhance its reactivity toward the $\pi$ allylpalladium intermediates, site-selective functionalization of polyols would result since hydroxyls not interacting with this additive remain largely inert under the conditions ( 4 to 6 via $\mathbf{5}$, or, 4 to 8 via 7). More importantly, in this regime, switch of the reaction site could in principle be realized simply by tuning the properties (bulkiness, number of available binding sites, Brønsted basicity, etc.) of the Lewis acid additives. Compared with approaches to achieve selectivity switch through modifying the whole catalytic complex (e.g., Pd-ligand complex here) for each substrate, the advantage of our design lies in the greater ease and extent of changing the characters of Lewis acid additives. 

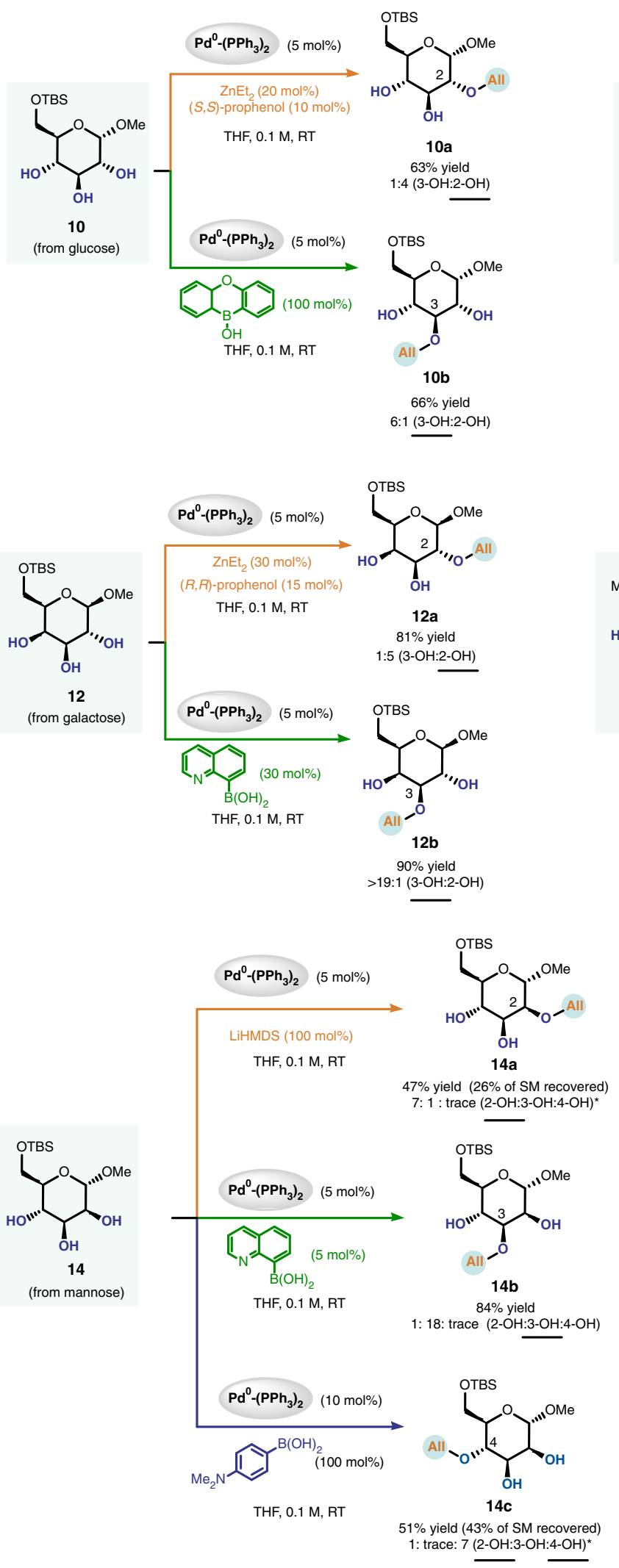
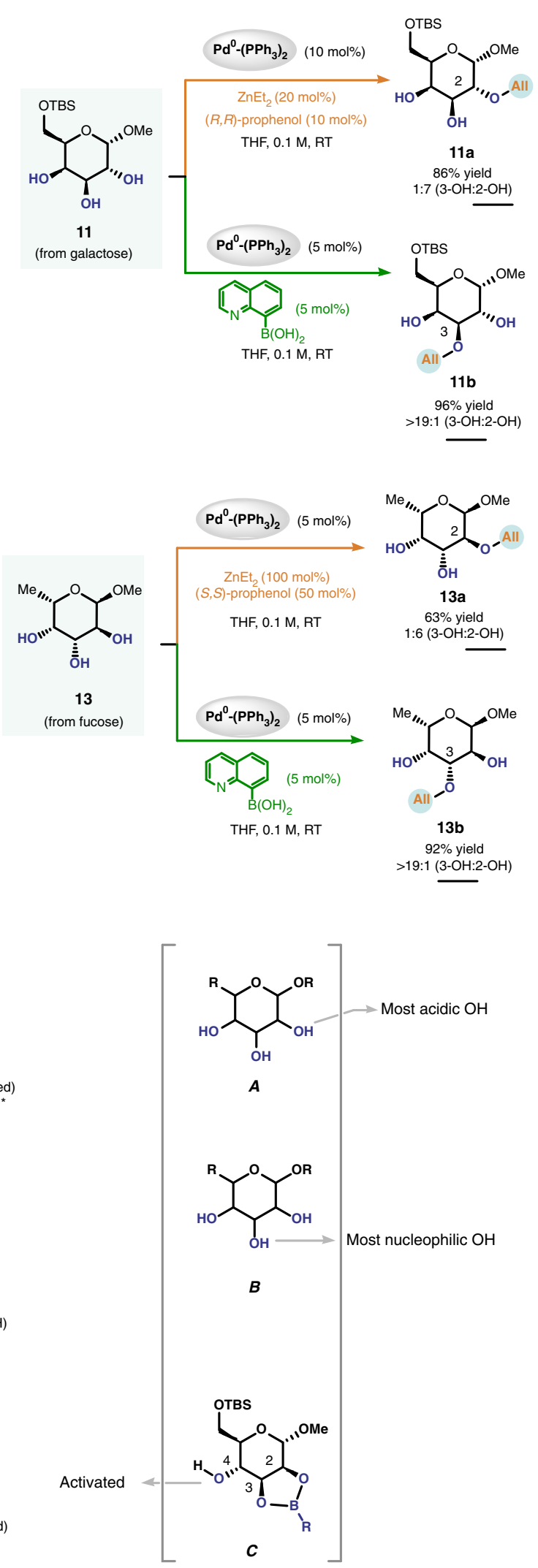

Fig. 3 Site-switchable mono-0-allylation of monosaccharides. Product ratios were determined by ${ }^{1} \mathrm{H}$ NMR analysis of crude reaction mixtures. Reported yields are isolated yields of products that are underlined. * A small amount of diallylated product was formed. See Supplementary Information for experimental details. L ligand. 


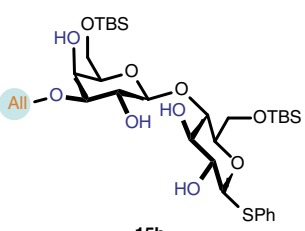

$73 \%$ yield $(22 \%$ of SM recovered) $>19: 1$ (3-OH:2-OH)

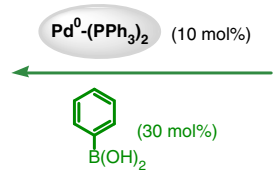

THF, $0.1 \mathrm{M}, \mathrm{RT}$

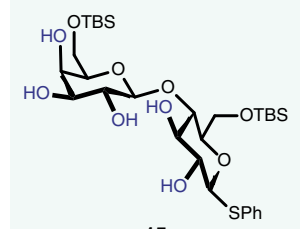

15

(from lactose)

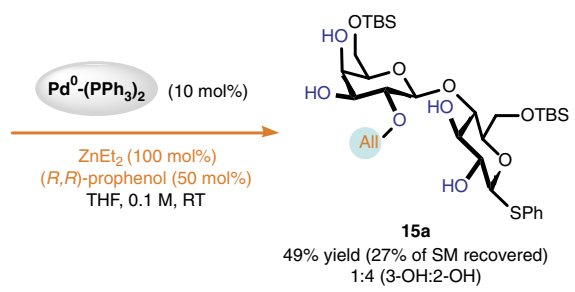

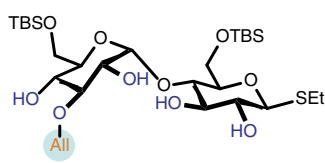

$16 \mathrm{~b}$ $85 \%$ yield $>19: 1$ (3-OH:2-OH)

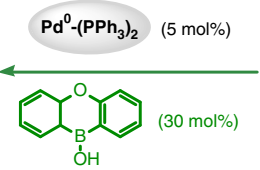

THF, $0.1 \mathrm{M}, \mathrm{RT}$

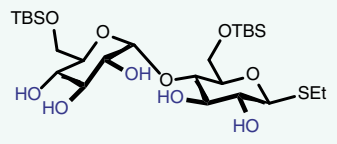

16

(from maltose)

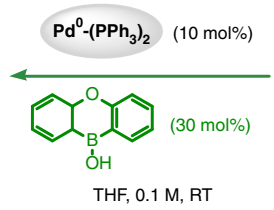

THF, $0.1 \mathrm{M}, \mathrm{RT}$

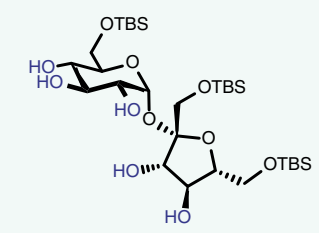

17

(from sucrose)
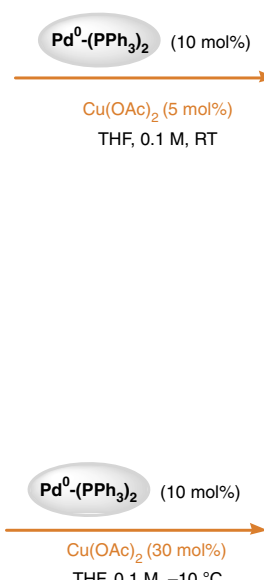

THF, $0.1 \mathrm{M},-10{ }^{\circ} \mathrm{C}$

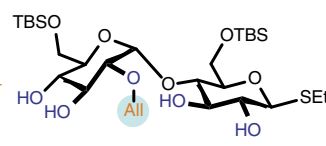

$16 \mathrm{a}$ $56 \%$ yield ( $16 \%$ of SM recovered) 1:4 (3-OH:2-OH)

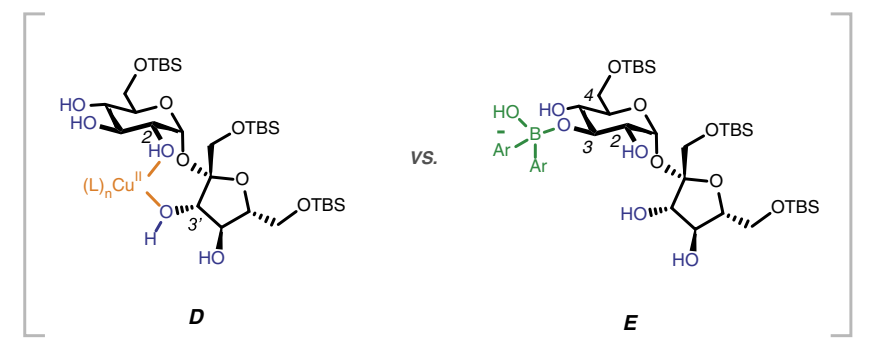

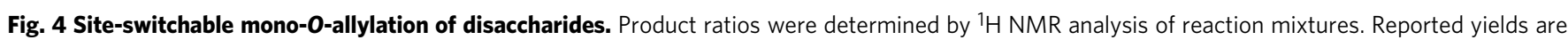
isolated yields of products that are underlined. See Supplementary Information for experimental details.

The validity of our design was first established in the sitedivergent mono-O-allylation of glucopyranoside 9 (Fig. 2c). Compound 9 contains two vicinal, equatorial hydroxyl groups that are similarly reactive toward an electrophilic $\pi$-allylpalladium intermediate. Under the standard Pd-catalyzed $\mathrm{O}$-allylation conditions and in the absence of any additives, the $\mathrm{C} 2-\mathrm{OH}$ modified product $9 \mathbf{a}$ and the $\mathrm{C} 3-\mathrm{OH}$ modified $\mathbf{9 b}$ were formed in almost equal amounts (entry 1, Fig. 2c). We then attempted adding each of the Lewis acid complexes listed in Fig. 2c individually to the reaction mixture so as to explore their effects on the site-selectivity profile of this transformation (entry 2-7). We found that the use of $\mathrm{Ph}_{2} \mathrm{BOH}$ as an additive resulted in the predominant formation of $\mathbf{9 b}$ in an efficient fashion (entry 6). Notably, the O'Doherty group ${ }^{40,41}$ reported the use of $\mathrm{Ph}_{2} \mathrm{BOH}$ to achieve Pd-catalyzed site-selective glycosylation. More intriguingly, the use of $\mathrm{MgBu}_{2}$ as an additive led to the preferential formation of the other isomer $\mathbf{9 a}$, albeit with moderate selectivity (entry 7). Further optimization of reaction conditions revealed that simultaneous addition of $\mathrm{MgBu}_{2}$ with BINOL afforded $9 \mathbf{a}$ in dramatically improved site-selectivity and efficiency (entry 8 ). Thus, we identified two sets of conditions that install an allyl group onto the two different hydroxyl groups in $\mathbf{9}$ (see below for a mechanistic rationalization). These conditions employ an identical transition metal complex [i.e., $\mathrm{Pd}^{0}-\left(\mathrm{PPh}_{3}\right)_{2}$ ] and differ only in the oxophilic additives utilized [Mg(II) vs. B(III)]. Collectively, these results validated the proof of principle of a strategically distinct approach to achieve reagent-controlled, site-switchable modification of polyols.

Reaction scope. Following the above protocol, we proceeded to explore the generality of our strategy. We first examined this method in the site-selective modification of various 


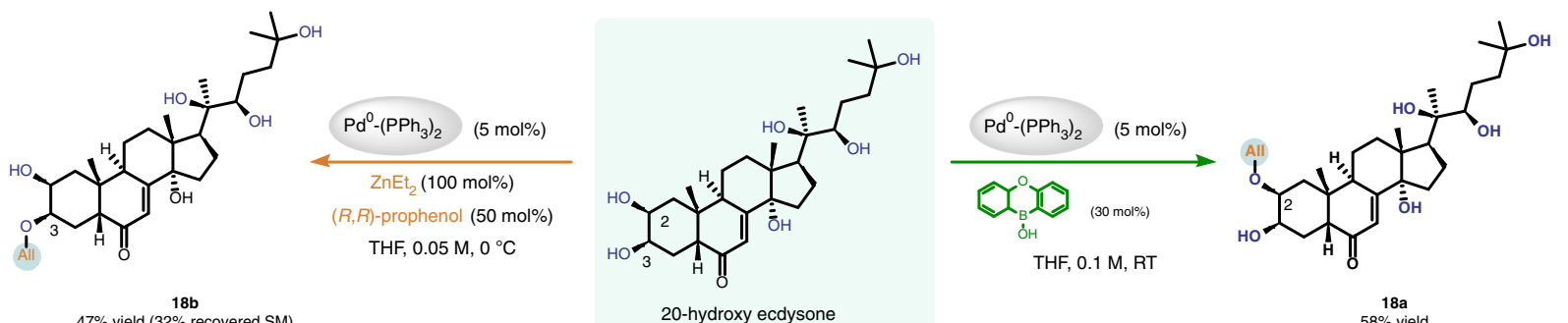

$47 \%$ yield $(32 \%$ recovered $\mathrm{SM})$

:4 (C2-OH:C3'-OH)

18

$58 \%$ yield
$2.4: 1$ (C2-OH:C3'-OH)

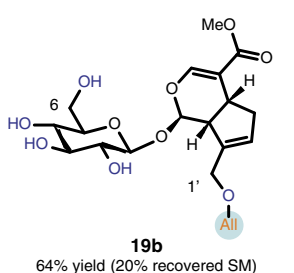

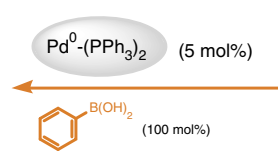

THF, $0.1 \mathrm{M}, \mathrm{RT}$

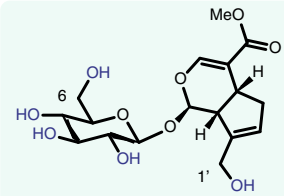

Geniposide

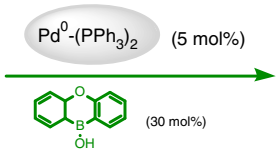

$\mathrm{THF}, 0.1 \mathrm{M}, 0{ }^{\circ} \mathrm{C}$

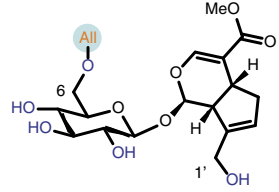

$19 a$

$55 \%$ yield $(32 \%$ recovered SM)
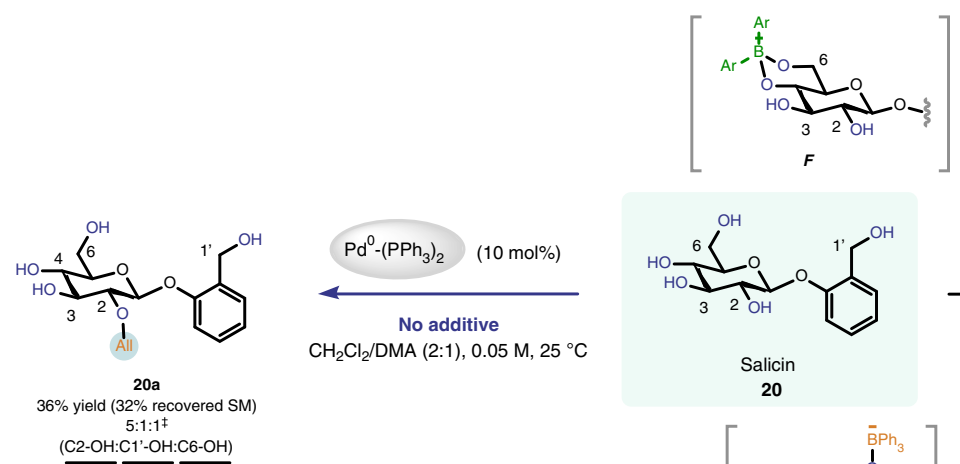

$\mathrm{CH}_{2} \mathrm{Cl}_{2} / \mathrm{DMA}(2: 1), 0.05 \mathrm{M}, 25^{\circ} \mathrm{C}$

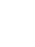

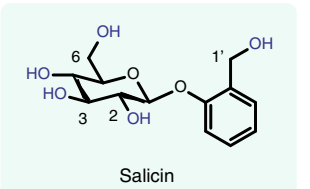

Salicin
20

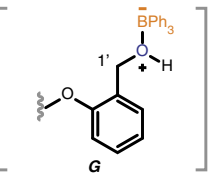

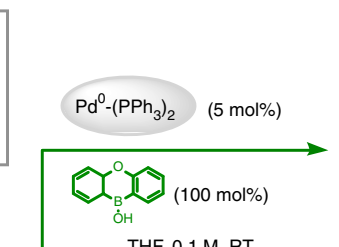

THF, 0.1 M, RT

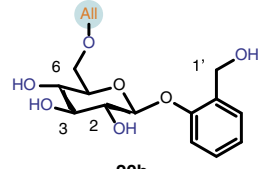

$20 \mathrm{~b}$

$64 \%$ yield ( $35 \%$ recovered $\mathrm{SM})$ $6: 1^{\star}\left(\mathrm{C} 6-\mathrm{OH}: \mathrm{C1}^{\prime}-\mathrm{OH}\right)$
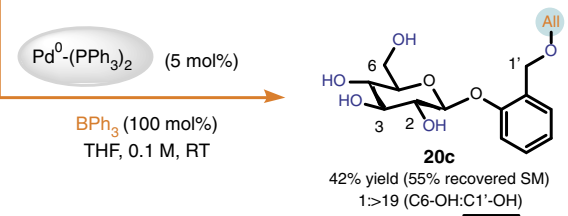

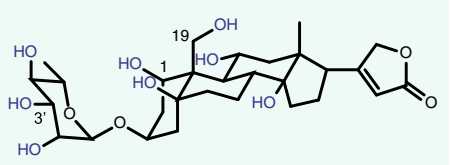

Ouabain

21

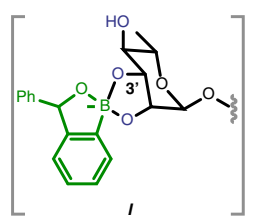

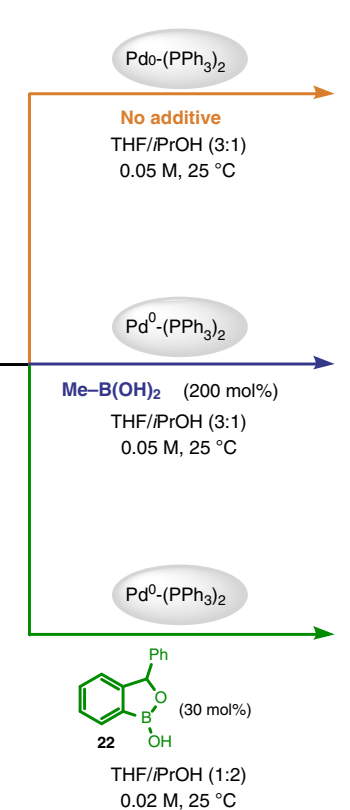

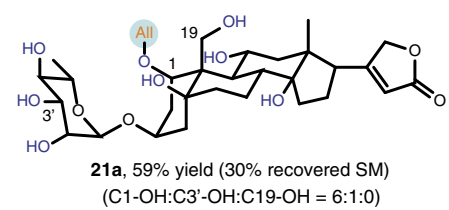

(C1-OH:C3'-OH:C19-OH = 6:1:0)

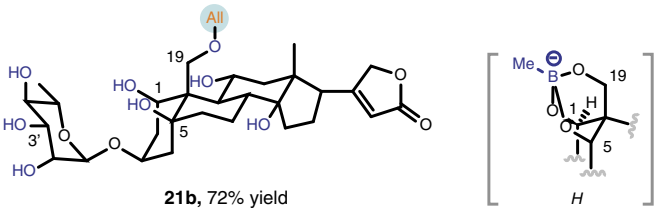

(C1-OH:C3'-OH:C19-OH = 1:1:>19)

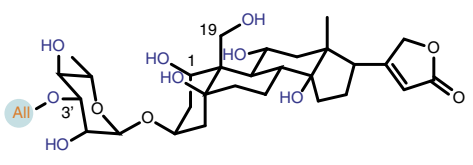

21c, $62 \%$ yield ${ }^{*}$

(C1-OH:C3'-OH:C19-OH = 1: >19:1)

Fig. 5 Site-switchable mono-0-allylation of polyhydroxylated natural products. Product ratios were determined by ${ }^{1} \mathrm{H}$ NMR analysis of crude reaction mixtures. Reported yields are isolated yields of products that are underlined. ${ }^{\star} \mathrm{A}$ small amount of diallylated product was also formed. ${ }^{\star} \mathrm{Small}$ amounts of $\mathrm{C} 3-\mathrm{OH}$ and $\mathrm{C} 4-\mathrm{OH}$ modified products were also formed. DMA, $\mathrm{N}, \mathrm{N}$-dimethyl acetamide. See Supplementary Information for experimental details. 
a

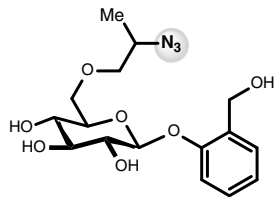

22a

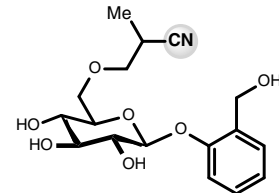

22b

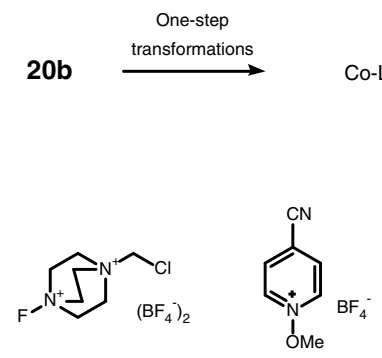

Selectfluor

Py-I

$64 \%, d r=1: 1$

$72 \%, d r=1: 1$

$\mathrm{Co}-\mathrm{L}^{*}, \mathrm{tBuOOH}, \mathrm{PhSiH}_{3}, \mathrm{TsCN}$

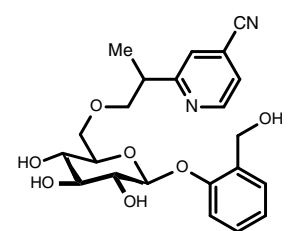

22d $\mathrm{Co}(\mathrm{acac})_{2}$, $\mathrm{BuOOH}, \mathrm{Et}_{3} \mathrm{SiH}, \mathrm{Py}-\mathrm{I}$

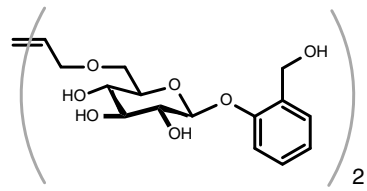

22e

$76 \%, E / Z=7: 3$

Grubbs I catalyst

b

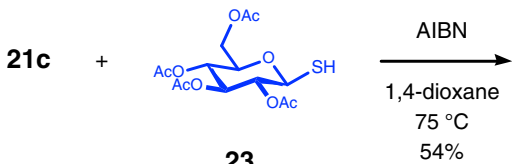

23

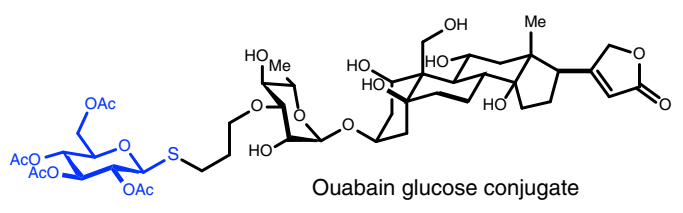

24

Fig. 6 Product derivatization. a Derivatization of 20b. b Derivatization of 21c. Product ratios were determined by ${ }^{1} \mathrm{H}$ NMR analysis of crude reaction mixtures. See Supplementary Information for experimental details. $L^{\star}=(R, R)-(-)-N, N^{\prime}-B i s(3,5-d i$-tert-butylsalicylidene)-1,2-cyclohexanediamine. ox oxalate.

monosaccharides (Fig. 3), including those derived from glucose (10), galactose (11-12), and fucose (13). All of these monosaccharides contain three contiguous secondary hydroxyls. In these cases, the allylation occurs at the $\mathrm{C} 3-\mathrm{OH}$ of the pyranose ring if an organoboron compound ${ }^{42}$ was used as additive (green arrows), but at the $\mathrm{C} 2-\mathrm{OH}$ when $\mathrm{ZnEt}_{2}$-prophenol complex ${ }^{43}$ was employed (orange arrows). To rationalize the switchable siteselectivity observed in these cases (10-13, Fig. 3) and in the case of 9 (Fig. 2c), we propose that the $\mathrm{C} 3-\mathrm{OH}$ is the most nucleophilic ${ }^{44}$ hydroxyl in each of these substrates, and it therefore most readily complexes with the organoboron compound (cf. structure A). The $\mathrm{C} 2-\mathrm{OH}$, on the other hand, is most readily deprotonated by a base since it is closest to the electron-withdrawing anomeric center (cf. structure B).

Each of the three hydroxyls in mannopyranoside 14 could be selectively alkylated in a controllable manner. As can be explained by the structures $\mathbf{A}$ and $\mathbf{B}$ shown above, the use of LiHMDS (orange arrow) and quinolin-8-ylboronic acid (green arrow) furnished the $\mathrm{C} 2-\mathrm{OH}$ allylated product $\mathbf{1 4 a}$ and the $\mathrm{C} 3-\mathrm{OH}$ allylated product $\mathbf{1 4 b}$, respectively. The $\mathrm{C} 4-\mathrm{OH}$ allylated product 14c could be obtained by using 4-dimethylaminophenylboronic acid, which, through formation of a stable boronic ester (cf. structure $\mathbf{C}$ ), deactivates the $\mathrm{C} 2-\mathrm{OH}$ and $\mathrm{C} 3-\mathrm{OH}^{45}$ and simultaneously enhances the reactivity of the $\mathrm{C} 4-\mathrm{OH}$ position.

We then showed this strategy could be adopted toward the siteswitchable allylation of structurally more complex disaccharides (Fig. 4). For example, the lactose derivative 15 contains five free hydroxyl groups. The use of $\mathrm{ZnEt}_{2}$-prophenol complex directed the allyl group to the $\mathrm{C} 2-\mathrm{OH}$ of $\mathbf{1 5}$ with high selectivity (orange arrow). Switching the additive to phenylboronic acid altered the preferential reaction site to the $\mathrm{C} 3-\mathrm{OH}$ (green arrow). Moving to maltoside 16, we found the use of Taylor's catalyst ${ }^{46}(10 \mathrm{H}$ dibenzo[b,e] $[1,4]$ oxaborinin-10-ol) guided the installation of the allyl group to the $\mathrm{C} 3-\mathrm{OH}$, while employment of $\mathrm{Cu}(\mathrm{OAc})_{2}$ steered the allyl group to the $\mathrm{C} 2-\mathrm{OH}$ instead. It is worth noting that synthetically versatile but chelating thioether groups present in $\mathbf{1 5}$ and 16 were well tolerated by our conditions. We further applied this method to the site-divergent modification of fructoside 17, which contains a pyranoside ring linked to a furanoside ring. We precisely delivered the allyl group to the $\mathrm{C} 3-\mathrm{OH}$ of the pyranoside ring using Taylor's catalyst as an additive, or to the $\mathrm{C}^{\prime}$ '-OH of the furanoside ring if applying $\mathrm{Cu}(\mathrm{OAc})_{2}$, instead. Here, we rationalize that Taylor's catalyst complexes with the $\mathrm{C} 3-\mathrm{OH}$ of the pyranose ring (see structure $\mathrm{E}$ ), but $\mathrm{Cu}(\mathrm{OAc})_{2}$ chelates $^{47}$ with the $\mathrm{C} 2-\mathrm{OH}$ and the $\mathrm{C} 3$ '-OH of 17 and activates the $\mathrm{C} 3$ '- $\mathrm{OH}$ (cf. structure D). It is worth highlighting that, in this case, the selectivity switches between two hydroxyls that are six atoms apart. Therefore, it would be challenging to achieve a selectivity switch between these two hydroxyls through designing Pd-ligand complexes.

Modification of natural products. We continued to apply our strategy to the site-switchable modification of polyhydroxylated natural products (Fig. 5). 20-Hydroxyecdysone (18) is an ecdysteroid hormone that controls the metamorphosis and ecdysis of arthropods. This compound contains six free hydroxyls, three of which are secondary. Site-divergent modification of $\mathbf{1 8}$ could be achieved. If Taylor's catalyst was employed as additive, the allylation occurred preferentially at the $\mathrm{C} 2-\mathrm{OH}$ (green arrow), whereas if $\mathrm{Zn}$ (II)-Prophenol complex was used, the allylation occurred at the $\mathrm{C} 3-\mathrm{OH}$ (orange arrow). Geniposide (19) is an iridoid glycoside that exhibits diverse biological activities. In addition to five free hydroxyls, this compound also contains a sensitive enol ether moiety and an enoate ester group. Employing our strategy, we could selectively install an allyl group to the $\mathrm{C6}-\mathrm{OH}$ of the glucose 
ring employing Taylor's catalyst, or to the $\mathrm{C1}$ '-OH with phenylboronic acid as an additive. Here, the site of reaction switches cleanly between two primary hydroxyls.

Following the above principle, we were able to selectively modify up to three different hydroxyl groups within some complex polyols. For example, salicin (19) is a natural product that acts as an anti-inflammatory agent in the human body. The $\mathrm{C} 2-\mathrm{OH}$ of the glucopyranoside ring in $\mathbf{1 9}$ is intrinsically the most reactive hydroxyl and gets allylated preferentially in the absence of any additives (blue arrow). Intriguingly, applying Taylor's catalyst as an additive in the standard reaction conditions delivered the allyl group to the $\mathrm{C} 6-\mathrm{OH}$ of 19 (green arrow), presumably via the intermediacy of the ate complex $\mathbf{F}$. If the bulky, monovalent $\mathrm{BPh}_{3}$ was employed instead (orange arrow), the allylation occurs at the benzylic hydroxyl $\left(\mathrm{Cl}^{\prime}-\mathrm{OH}\right)$ with high site-selectivity (cf. G). Thus, three individual hydroxyls within salicin could be selectively modified in a controllable fashion.

Ouabain (21) exhibits potent antiproliferative activities against several cancer cell lines at nanomolar concentrations ${ }^{48,49}$. This molecule contains eight free hydroxyls, including one primary, five secondary, and two tertiary ones. When no Lewis acid additive is used, the Pd-catalyzed allylation occurs at the secondary $\mathrm{C} 1-\mathrm{OH}$ to afford 21a with decent selectivity and efficiency (orange arrow). When we used methylboronic acid as an additive, the primary $\mathrm{C} 19-\mathrm{OH}$ was selectively modified to give product $\mathbf{2 1 b}$ in high yield (blue arrow). We hypothesize that methylboronic acid simultaneously complexed with the $\mathrm{C} 1-\mathrm{OH}$, $\mathrm{C} 5-\mathrm{OH}$ and $\mathrm{C} 19-\mathrm{OH}$ of $\mathbf{2 1}$ (see structure $\mathbf{H}$ ), and activated the least hindered primary hydroxyl in the Pd-catalyzed allylation reactions. If the oxaborole derivative $\mathbf{2 2}$ was employed instead, the site-selectivity changed again. This time the $\mathrm{C} 3{ }^{\prime}-\mathrm{OH}$ of the sugar ring was modified with high efficiency (green arrow). We assume that the bulky oxaborole $\mathbf{2 2}$ will preferentially form an ate complex with the vicinal diol moiety in the sugar ring (see structure I), which renders the equatorial C3'-OH most reactive. Lastly, the group that can be transferred by our method is not restricted to the parent allyl unit. For instance, cinnamyl groups bearing various substituents could be installed onto ouabain with good site-selectivities as well, if the corresponding electrophiles are employed (see Supplementary Fig. 3).

Product derivatization. To further demonstrate the utility of this method as a tool for the late stage functionalization of naturally occurring polyols, we have performed the reactions shown in Fig. 6 . We show that the alkene group installed on salicin could be conveniently converted to a variety of other functional groups in one step (Fig. 6a). For instance, we showed that a cobalt-catalyzed hydroazidation reaction ${ }^{50}$ smoothly incorporated an azide group onto 20b. The resulting product $\mathbf{2 2 a}$ is thus primed for the venerable azide alkyne coupling reactions ${ }^{51}$ that are extensively utilized in the fields of chemical biology and material science. By using similar hydrofunctionalization reactions of alkenes, we also successfully attached a nitrile ${ }^{52}$ group (22b), a fluorine ${ }^{53}$ atom (22c), or a pyridine $\mathrm{e}^{54}$ ring (22d) onto the target molecule. Furthermore, a cross-metathesis reaction ${ }^{55}$ readily converted $20 \mathrm{~b}$ to a dimeric structure 22e. Lastly, we prepared a conjugate of ouabain and glucose (24) from $21 \mathrm{c}$ and $\mathbf{2 3}$, taking advantage of the potent thiol-ene click reaction ${ }^{56}$. Therefore, when coupled with the synthetic versatility of alkenes, our site-switchable $O$-allylation reaction provides rapid and efficient accesses to derivatives and analogues of complex polyols.

\section{Discussion}

This study showcased the power of a dual catalytic strategy for site-switchable modification of target molecules, a key challenge in chemistry. This design allocates the task of activating electrophiles and that of controlling site-selectivity to, respectively, the Pd-catalyst and the Lewis acid additive. Thus, switch of reaction site was achieved simply through changing the identity of Lewis acid additives, a tactic that has not been systematically explored before. The allyl unit installed by this method could serve as an entry point to various other functional groups. We anticipate that the generality, immediate utility, and the operational ease of this method will inspire further exploration that ultimately leads to precise control of site-selectivity during modification of complex compounds.

\section{Methods}

Synthesis of 9a. In a $\mathrm{N}_{2}$-filled glovebox, $n \mathrm{Bu}_{2} \mathrm{Mg}(1 \mathrm{M}$ in heptane, Energy Chemicals, Lot DL140184, $45 \mu \mathrm{L}, 0.045 \mathrm{mmol}, 0.3$ equiv), ( \pm )-BINOL ( $8.6 \mathrm{mg}$, Energy Chemicals Lot DI240132, $0.03 \mathrm{mmol}, 0.2$ equiv) and THF $(200 \mu \mathrm{L})$ were weighed into a screw capped vial (labeled as Vial A) containing a stir bar. The mixture was stirred for $5 \mathrm{~min}$, at which time compound 9 (42.6 mg, $0.15 \mathrm{mmol}, 1.0$ equiv) was added. The resulting solution was stirred for an additional $30 \mathrm{~min}$.

To another vial, compound $2\left(36.4 \mathrm{mg}, 0.23 \mathrm{mmol}, 1.5\right.$ equiv), $\mathrm{Pd}_{2}(\mathrm{dba})_{3} \cdot \mathrm{CHCl}_{3}$ ( $7.8 \mathrm{mg}, 7.5 \mu \mathrm{mol}, 0.05$ equiv), $\mathrm{PPh}_{3}$ ( $7.8 \mathrm{mg}, 0.03 \mathrm{mmol}, 0.2$ equiv), and THF (200 $\mu \mathrm{L})$ were added in sequence. The mixture was stirred for $10 \mathrm{~min}$, and then transferred to Vial A. An additional portion of THF $(2.6 \mathrm{~mL})$ was added to Vial A so that [9] was adjusted to $0.05 \mathrm{M}$. Vial A was tightly capped, taken out of the glovebox, and stirred at $-10{ }^{\circ} \mathrm{C}$ for $12 \mathrm{~h}(400 \mathrm{rpm})$. The reaction mixture was then concentrated in vacuo. An aliquot of the residue was taken for ${ }^{1} \mathrm{H}$ NMR analysis, which indicated that products $9 \mathbf{a}$ and $\mathbf{9 b}$ were formed in a ratio of ca. 10:1. Flash chromatography $\left(\mathrm{SiO}_{2}\right)$ using petroleum ether/EtOAc $(6: 1-3: 1)$ as eluent afforded 9a as a yellow solid (41 mg, $0.127 \mathrm{mmol}, 83 \%$ ).

Synthesis of 9b. In a $\mathrm{N}_{2}$-filled glovebox, compound 9 (56.5 mg, $0.20 \mathrm{mmol}, 1.0$ equiv) and 2-(diphenylboryloxy)-ethanamine (2.4 mg, Aladdin Lot J1824016, 0.01 mmol, $5 \mathrm{~mol} \%)$, and THF $(500 \mu \mathrm{L})$ were weighed into a screw capped vial (labeled as Vial A) containing a stir bar. The resulting solution was stirred for an additional $30 \mathrm{~min}$.

To another vial, compound 2 (38.0 mg, $0.24 \mathrm{mmol}, 1.2$ equiv), $\mathrm{Pd}_{2}(\mathrm{dba})_{3} \cdot \mathrm{CHCl}_{3}$ (5.2 mg, $5 \mu \mathrm{mol}, 0.025$ equiv), $\mathrm{PPh}_{3}$ (5.2 mg, $0.02 \mathrm{mmol}, 0.1$ equiv), and THF (200 $\mu \mathrm{L}$ ) were added in sequence. The mixture was stirred for $10 \mathrm{~min}$, and then transferred to Vial A. An additional portion of THF $(0.3 \mathrm{~mL})$ was added to Vial A so that [9] was adjusted to $0.2 \mathrm{M}$. Vial A was tightly capped, taken out of the glovebox, and stirred at $25^{\circ} \mathrm{C}$ (outside temperature) for $12 \mathrm{~h}(400 \mathrm{rpm})$. The reaction mixture was then concentrated in vacuo. An aliquot of the residue was taken for ${ }^{1} \mathrm{H}$ NMR analysis, which indicated that products $9 \mathbf{a}$ and $9 \mathbf{b}$ were formed in a ratio of $1: 13$. Flash chromatography $\left(\mathrm{SiO}_{2}\right)$ using petroleum ether/EtOAc (3:1-1:1) as eluent afforded $\mathbf{9 b}$ as a pale yellow oil (55.4 $\mathrm{mg}, 0.172 \mathrm{mmol}, 86 \%)$.

\section{Data availability}

Additional data supporting the findings described in this paper are available in the Supplementary Information, and also are available from the corresponding author upon reasonable request.

Received: 30 July 2020; Accepted: 2 October 2020; Published online: 10 November 2020

\section{References}

1. Cernak, T., Dykstra, K. D., Tyagarajan, S., Vachal, P. \& Krska, S. W. The medicinal chemist's toolbox for late stage functionalization of drug-like molecules. Chem. Soc. Rev. 45, 546-576 (2016).

2. Yoganathan, S. \& Miller, S. J. Structure diversification of vancomycin through peptide-catalyzed, site-selective lipidation: a catalysis-based approach to combat glycopeptide-resistant pathogens. J. Med. Chem. 58, 2367-2377 (2015).

3. Toste, F. D., Sigman, M. S. \& Miller, S. J. Pursuit of noncovalent interactions for strategic site-selective catalysis. Acc. Chem. Res. 50, 609-615 (2017).

4. Hartwig, J. F. Catalyst-controlled site-selective bond activation. Acc. Chem. Res. 50, 549-555 (2017).

5. Huang, Z. \& Dong, G. Site-selectivity control in organic reactions: a quest to differentiate reactivity among the same kind of functional groups. Acc. Chem. Res. 50, 465-471 (2017).

6. Mahatthananchai, J., Dumas, A. M. \& Bode, J. W. Catalytic selective synthesis. Angew. Chem., Int. Ed. 51, 10954-10990 (2012). 
7. Li, J. et al. Site-specific allylic C-H bond functionalization with a copperbound N-centred radical. Nature 574, 516-521 (2019).

8. Tadross, P. M. \& Jacobsen, E. N. Remodelling by diversity and design. Nat. Chem. 4, 963-965 (2012).

9. Shugrue, C. R. \& Miller, S. J. Applications of nonenzymatic catalysts to the alteration of natural products. Chem. Rev. 117, 11894-11951 (2017).

10. Giuliano, M. W. \& Miller, S. J. Site-selective reactions with peptide-based catalysts. Top. Curr. Chem. 372, 157-201 (2016).

11. Davies, H. M. L. \& Liao, K. Dirhodium tetracarboxylates as catalysts for selective intermolecular C-H functionalization. Nat. Rev. Chem. 3, 347-360 (2019).

12. White, M. C. \& Zhao, J. Aliphatic C-H oxidations for late-stage functionalization. J. Am. Chem. Soc. 140, 13988-14009 (2018).

13. Lichtor, P. A. \& Miller, S. J. Combinatorial evolution of site- and enantioselective catalysts for polyene epoxidation. Nat. Chem. 4, 990-995 (2012).

14. Wilcock, B. C. et al. Electronic tuning of site-selectivity. Nat. Chem. 4, 996-1003 (2012).

15. Brückl, T., Baxter, R. D., Ishihara, Y. \& Baran, P. S. Innate and guided C-H functionalization logic. Acc. Chem. Res. 45, 826-839 (2011).

16. Davies, H. M. L., Du Bois, J. \& Yu, J.-Q. C-H functionalization in organic synthesis. Chem. Soc. Rev. 40, 1855-1856 (2011).

17. Bertozzi, C. R. \& Kiessling, L. L. Chemical glycobiology. Science 291, 2357-2364 (2001).

18. Seeberger, P. H. \& Werz, D. B. Synthesis and medical applications of oligosaccharides. Nature 446, 1046-1051 (2007).

19. Wong, C.-H. Carbohydrate-Based Drug Discovery (Wiley, 2003).

20. Werz, D. B. \& Vidal, S. Modern Synthetic Methods in Carbohydrate Chemistry: From Monosaccharides to Complex Glycoconjugates (Wiley, 2014).

21. Jäger, M. \& Minnaard, A. J. Regioselective modification of unprotected glycosides. Chem. Commun. 52, 656-664 (2016).

22. Dimakos, V. \& Taylor, M. S. Site-selective functionalization of hydroxyl groups in carbohydrate derivatives. Chem. Rev. 118, 11457-11517 (2018).

23. Sculimbrene, B. R. \& Miller, S. J. Discovery of a catalytic asymmetric phosphorylation through selection of a minimal kinase mimic: a concise total synthesis of D-myo-inositol-1-phosphate. J. Am. Chem. Soc. 123, 10125-10126 (2001).

24. Griswold, K. S. \& Miller, S. J. A peptide-based catalyst approach to regioselective functionalization of carbohydrates. Tetrahedron 59, 8869-8875 (2003).

25. Fowler, B. S., Laemmerhold, K. M. \& Miller, S. J. Catalytic site-selective thiocarbonylations and deoxygenations of vancomycin reveal hydroxyldependent conformational effects. J. Am. Chem. Soc. 134, 9755-9761 (2012).

26. Han, S. \& Miller, S. J. Asymmetric catalysis at a distance: catalytic, siteselective phosphorylation of teicoplanin. J. Am. Chem. Soc. 135, 12414-12421 (2013).

27. Allen, C. L. \& Miller, S. J. Chiral copper(II) complex-catalyzed reactions of partially protected carbohydrates. Org. Lett. 15, 6178-6181 (2013).

28. Chen, I. H., Kou, K. G. M., Le, D. N., Rathbun, C. M. \& Dong, V. M. Recognition and site-selective transformation of monosaccharides by using copper(II) catalysis. Chem. Eur. J. 20, 5013-5018 (2014).

29. Kawabata, T., Muramatsu, W., Nishio, T., Shibata, T. \& Schedel, H. A catalytic one-step process for the chemo- and regioselective acylation of monosaccharides. J. Am. Chem. Soc. 129, 12890-12895 (2007).

30. Ueda, Y., Mishiro, K., Yoshida, K., Furuta, T. \& Kawabata, T. Regioselective diversification of a cardiac glycoside, lanatoside C, by organocatalysis. J. Org. Chem. 77, 7850-7857 (2012).

31. Yamada, T. et al. Organocatalytic site-selective acylation of avermectin B, A unique endectocidal drug. Chem. Pharm. Bull. 64, 856-864 (2016).

32. Sun, X., Lee, H., Lee, S. \& Tan, K. L. Catalyst recognition of cis-1,2-diols enables site-selective functionalization of complex molecules. Nat. Chem. $\mathbf{5}$ 790-795 (2013).

33. Tay, J.-H. et al. Regiodivergent glycosylations of 6-deoxy-erythronolide B and oleandomycin-derived macrolactones enabled by chiral acid catalysis. J. Am. Chem. Soc. 139, 8570-8578 (2017).

34. Li, R.-Z. et al. Site-divergent delivery of terminal propargyls to carbohydrates by synergistic. Catal. Chem. 3, 834-845 (2017).

35. Xiao, G. et al. Catalytic site-selective acylation of carbohydrates directed by cation-n interaction. J. Am. Chem. Soc. 139, 4346-4349 (2017).

36. Krautwald, S., Sarlah, D., Schafroth, M. A. \& Carreira, E. M. Enantio- and diastereodivergent dual catalysis: $\alpha$-allylation of branched aldehydes. Science 340, 1065-1068 (2013)

37. Wang, H., La Russa, M. \& Qi, L. S. CRISPR/Cas9 in genome editing and beyond. Annu. Rev. Biochem. 85, 227-264 (2016).

38. Wade, L. G. Organic Chemistry pp. 328-391 (Prentice Hall, 2012).

39. Trost, B. M. Metal catalyzed allylic alkylation: its development in the trost laboratories. Tetrahedron 71, 5708-5733 (2015).
40. Trost, B. M., McEachern, E. J. \& Toste, D. F. A two-component catalyst system for asymmetric allylic alkylations with alcohol pronucleophiles. J. Am. Chem. Soc. 120, 12702-12703 (1998).

41. Bajaj, S. O., Sharif, E. U., Akhmedov, N. G. \& O’Doherty, G. A. De novo asymmetric synthesis of the Mezzettiaside family of natural products via the iterative use of a dual B-/Pd-catalyzed glycosylation. Chem. Sci. 5, 2230-2234 (2014).

42. Wu, X. et al. Selective sensing of saccharides using simple boronic acids and their aggregates. Chem. Soc. Rev. 42, 8032-8048 (2013).

43. Trost, B. M. \& Bartlett, M. J. ProPhenol-catalyzed asymmetric additions by spontaneously assembled dinuclear main group metal complexes. Acc. Chem. Res. 48, 688-701 (2015).

44. Shang, W. et al. Site-selective O-arylation of glycosides. Angew. Chem. Int. Ed. 57, 314-318 (2018)

45. Dimakos, V., Garrett, G. E. \& Taylor, M. S. Site-selective, copper-mediated Oarylation of carbohydrate derivatives. J. Am. Chem. Soc. 139, 15515-15521 (2017).

46. Taylor, M. S. Catalysis based on reversible covalent interactions of organoboron compounds. Acc. Chem. Res. 48, 295-305 (2015).

47. Matsui, Y. et al. The formation and structure of copper(II) complexes with cyclodextrins in an alkaline solution. Bull. Chem. Soc. Jpn. 48, 2187-2191 (1975).

48. Renata, H., Zhou, Q. \& Baran, P. S. Strategic redox relay enables a scalable synthesis of ouabagenin, a bioactive cardenolide. Science 339, 59-63 (2013).

49. Guerrero, A. et al. Cardiac glycosides ae broad-spectrum senolytics. Nat. Metab. 1, 1074-1088 (2019).

50. Waser, J., Gaspar, B., Nambu, H. \& Carreira, E. M. Hydrazines and azides via the metal-catalyzed hydrohydrazination and hydroazidation of olefins. J. Am. Chem. Soc. 128, 11693-11712 (2006).

51. Kolb, H. C., Finn, M. G. \& Sharpless, K. B. Click chemistry: diverse chemical function from a few good reactions. Angew. Chem. Int. Ed. 40, 2004-2021 (2001).

52. Gaspar, B. \& Carreira, E. M. Mild cobalt-catalyzed hydrocyanation of olefins with tosyl cyanide. Angew. Chem. Int. Ed. 46, 4519-4522 (2007).

53. Barker, T. J. \& Boger, D. L. Fe(III)/NaBH4-mediated free radical hydrofluorination of unactivated alkenes. J. Am. Chem. Soc. 134, 13588-13591 (2012).

54. Ma, X. \& Herzon, S. B. Intermolecular hydropyridylation of unactivated alkenes. J. Am. Chem. Soc. 138, 8718-8721 (2016).

55. Schwab, P., France, M. B., Ziller, J. W. \& Grubbs, R. H. A series of well-defined metathesis catalysts-synthesis of $\left[\mathrm{RuCl}_{2}\left(=\mathrm{CHR}^{\prime}\right)\left(\mathrm{PR}_{3}\right)_{2}\right]$ and its reactions. Angew. Chem. Int. Ed. 34, 2039-2041 (1995).

56. Dondoni, A. The emergence of thiol-ene coupling as a click process for materials and bioorganic chemistry. Angew. Chem. Int. Ed. 47, 8995-8997 (2008).

\section{Acknowledgements}

This work was supported by funding from National Key Research and Development Program (2018YFA0903300), National Natural Science Foundation of China (Nos. 21922106 and 21772125), start-up funding from Sichuan University, and The Open Project of State Key Laboratory of Natural Medicines, No. 3144060211. We acknowledge Prof. Jason J. Chruma (SCU) for helpful discussions and manuscript revision.

\section{Author contributions}

D.N. conceived the idea, guided the project, and wrote the manuscript with feedbacks from other authors. H.T., Y.-B.T., H.C., R.-Z.L., and X.Z. performed the experiments and analyzed the results.

\section{Competing interests}

The authors declare no competing interests.

\section{Additional information}

Supplementary information is available for this paper at https://doi.org/10.1038/s41467 020-19348-x.

Correspondence and requests for materials should be addressed to D.N.

Peer review information Nature Communications thanks the anonymous reviewer(s) for their contribution to the peer review of this work.

Reprints and permission information is available at http://www.nature.com/reprints

Publisher's note Springer Nature remains neutral with regard to jurisdictional claims in published maps and institutional affiliations. 
(c) (i) Open Access This article is licensed under a Creative Commons Attribution 4.0 International License, which permits use, sharing, adaptation, distribution and reproduction in any medium or format, as long as you give appropriate credit to the original author(s) and the source, provide a link to the Creative Commons license, and indicate if changes were made. The images or other third party material in this article are included in the article's Creative Commons license, unless indicated otherwise in a credit line to the material. If material is not included in the article's Creative Commons license and your intended use is not permitted by statutory regulation or exceeds the permitted use, you will need to obtain permission directly from the copyright holder. To view a copy of this license, visit http://creativecommons.org/ licenses/by/4.0/.

(C) The Author(s) 2020 